\title{
Health-related quality of life and anxiety associated with childhood intermittent exotropia before and after surgical correction
}

Danyi Mao ${ }^{\dagger}$, Jing Lin ${ }^{\dagger}$, Lina Chen, Jiying Luo and Jianhua Yan ${ }^{*}$ (1)

\begin{abstract}
Background: Intermittent exotropia (IXT) is the most common form of exotropia in children. In addition to cosmetic effects and loss of stereoscopic function, IXT may negatively impact the psychological well-being of children and their parents. The purpose of this study was to assess the patient-reported outcomes of Chinese children with IXT before and after strabismus surgery.

Methods: The records of children with IXT who underwent strabismus surgery at the Zhongshan Ophthalmic Center of Sun Yat-sen University, China over the period from January 1, 2016 to December 31, 2018 were prospectively recruited. All children underwent ophthalmic and orthoptic examinations, including the prism and alternate cover test, fusion function by synoptophore, stereoacuity and Newcastle control score. Two patientreported outcome measures were used: the intermittent Exotropia Questionnaire (IXTQ) to measure disease-specific health-related quality of life (HRQOL) and the Hospital Anxiety and Depression Scale (HADS) to measure anxiety and depression. Patient-reported outcome measurements were made before and after surgery with responses from children and their parents.

Results: A total of 389 children were eligible for inclusion ( $47.8 \%$ male, $52.2 \%$ female, mean + SD age $=8.17 \pm 2.81$ ). Preoperative IXTQ scores in both children $(48.21 \pm 26.2)$ and their parents $(44.6 \pm 25.68)$ were significantly correlated with near stereoacuity $(P=0.029$ and $P=0.015$, respectively). The angle of deviation at near vision showed a negative linear relationship with visual function $(P=0.026)$ and psychological $(P=0.019)$ scores as well as opinions regarding surgery $(P=0.024)$. HADS scores (anxiety scale score: $11 \pm 2.92$, depression scale score: 10.44 \pm 2.9$)$ were also related to near stereoacuity $(P<0.05)$. After surgery, both children's $(74.83 \pm 16.59)$ and parents' $(68.57 \pm 17.06)$ IXTQ scores significantly improved $(p<0.01)$. Children's IXTQ scores were related to the angle of deviation at distance, and their psychological and visual function scores showed a negative relationship with the angle of deviation at near vision $(P<0.05)$.
\end{abstract}

\footnotetext{
*Correspondence: yanjh2011@126.com

${ }^{\dagger}$ Danyi Mao and Jing Lin contributed equally to this work.

State Key Laboratory of Ophthalmology, Zhongshan Ophthalmic Center, Sun

Yat-sen University, Guangzhou 510080, Guangdong, China
}

(c) The Author(s). 2021 Open Access This article is licensed under a Creative Commons Attribution 4.0 International License, which permits use, sharing, adaptation, distribution and reproduction in any medium or format, as long as you give appropriate credit to the original author(s) and the source, provide a link to the Creative Commons licence, and indicate if changes were made. The images or other third party material in this article are included in the article's Creative Commons licence, unless indicated otherwise in a credit line to the material. If material is not included in the article's Creative Commons licence and your intended use is not permitted by statutory regulation or exceeds the permitted use, you will need to obtain permission directly from the copyright holder. To view a copy of this licence, visit http://creativecommons.org/licenses/by/4.0/ The Creative Commons Public Domain Dedication waiver (http://creativecommons.org/publicdomain/zero/1.0/) applies to the data made available in this article, unless otherwise stated in a credit line to the data. 
Conclusion: Children and parents' HRQOL and HADS were associated with near stereoacuity. Parents usually attend more readily to the angle of deviation at near in their IXT children. HRQOL improved significantly after surgery and can be used as one of the indices for preoperative evaluation but is not recommended as a criterion for surgical intervention.

Keywords: Intermittent exotropia, Health-related quality of life, Hospital anxiety and depression scale

\section{Background}

Intermittent exotropia (IXT) is the most common form of exotropia in children [1]. The incidence in China ranges from 3.3 to $3.9 \%$ in the general population, which is much higher than that observed in Western populations [2-4]. In addition to cosmetic affects and loss of stereoscopic function [5], IXT may negatively impact the psychological well-being of children and their parents [6]. Health-related quality of life (HRQOL) represents an important tool for evaluating IXT patients, but it is rarely used by clinicians. When treating children with IXT, clinicians should focus not only on physiological parameters, such as the angle of deviation, Newcastle control score (NCS) and stereoacuity, but also on the psychological components assessed with HRQOL in these children and their parents. Surveys are currently available to perform these evaluations. For example, the Intermittent Exotropia Questionnaire (IXTQ) is a wellaccepted, specific tool to assess HRQOL in IXT children and their parents [7]. In addition, the Hospital Anxiety and Depression Scale (HADS) provides a reliable tool for determining depression and anxiety status for hospital outpatient services and an effective means to measure the severity of emotional disorders [8]. With the use of these patient proxy scales, it is possible to achieve a more detailed assessment of the impact of IXT on the mental health of these children.

At present, only rarely are the psychological problems of children with IXT considered. In general, the more severe the IXT, the worse the HRQOL. However, Hatt and Lim $[9,10]$ found that whereas parents' HRQOL was related to children's IXT severity, no such relationship was present in the children. In this way, the clinical findings of IXT in these children do not fully correspond with their mental health. Another indication of this difference between the children and their parents was the finding that parents with poorer HRQOL scores were more likely to make the decision to perform surgery [11]. Chiu et al. [12] suggested that HRQOL should be incorporated into postoperative evaluations. In support of this proposal are the results of McKenzie et al., who reported that IXT children, especially boys, are three times more likely to suffer from mental illness in the future [13].

As no clear criteria currently exist for surgical intervention in childhood IXT, this raises the issue as to whether HRQOL should be included as an indication for surgery as well as one of the criteria for evaluating surgical success. Although there are a few papers that have reported on anxiety and depression in adults with strabismus [14-16], to the best of our knowledge, no information regarding these factors is available in children with IXT and their parents. Therefore, the purpose of this study was to assess both the HRQOL and the HADS in a large sample of IXT children and their parents related to the severity of the IXT. In addition, we reexamined HRQOL after surgery to examine the relationship between cosmetic/functional recovery and HRQOL.

\section{Methods \\ Patients}

Children $(N=389)$ with IXT who underwent strabismus surgery at the Zhongshan Ophthalmic Center of Sun Yat-sen University, China over the period from January 1, 2016 to December 31, 2018 were recruited for this study. The following inclusion criteria were employed: (1) 5-17 years old, (2) basic type (the deviation was within $10 \Delta$ at distance and near), (3) angle of distant exodeviation $\geq 15$ prism diopters (PD), (4) no "A" or" V" pattern or vertical deviation, (5) best corrected visual acuity of no less than 20/30 and bilateral difference of not greater than two lines (for statistical analysis, the visual acuity would convert to $\log M A R$.) and (6) no abnormality in the anterior segment and fundus. The exclusion criteria included (1) a history of ophthalmic and/or strabismus surgery or botulinum injection, (2) previous vision training, (3) nystagmus, paralytic or restrictive exotropia, developmental delay and/or any learning disability and (4) any other neurological and/or psychological disorders. Informed consent was obtained from all patients and their parents. The study was compliant with the Declaration of Helsinki, and additional approval was obtained from the Research Ethics Board of the Zhongshan Ophthalmic Center of Sun Yat-sen University, China (approval NO. 2020KYPJ068).

\section{Clinical evaluation and surgical treatment}

All participants had undergone a comprehensive eye examination, including best corrected visual acuity, intraocular pressure, cycloplegic refraction, anterior segment examination by slit-lamp and fundus colour photography. The visual acuity was converted to 
$\operatorname{logMAR}$. Orthoptic examinations included the prism and alternate cover test (PACT) at distance $(6 \mathrm{~m})$ and near fixation $(33 \mathrm{~cm})$, fusion function by synoptophore, near stereoacuity $(33 \mathrm{~cm})$ by Titmus test, distance stereoacuity $(5 \mathrm{~m})$ by Randot test, NCS and the Worth 4 dot test. All patients underwent strabismus surgery under general anaesthesia. The surgical indication for IXT is that there is either definite evidence of existing defective binocular vision or gradual loss of fusional control. For the basic type of IXT, either bilateral rectus recession of the lateral rectus or unilateral recession of the lateral rectus and resection of the medial rectus of the nondominant eye is the right choice of surgical procedure. However, we prefer unilateral surgery. For cases with less than $25 \mathrm{PD}$ of exotropia, we usually perform only unilateral recession of the lateral rectus. A total of $69.9 \%$ of patients underwent unilateral lateral rectus recession and medial rectus resection, and $10 \%$ underwent bilateral lateral rectus recession, whereas $20.1 \%$ underwent unilateral lateral rectus recession. After a minimum period of 6 months of follow-up, exotropia of $\leq 10 \mathrm{PD}$ and esotropia $\leq 5 \mathrm{PD}$ were considered surgical success. Normal sensory fusion was classified as a patient who had simultaneous perception, fusion faculty and stereoacuity, and if any one of those functions was impaired, it was classified as abnormal.

\section{HADS}

The 14 items comprising the HADS serve to measure anxiety and depression symptoms, with seven items for the anxiety scale (HADS anxiety) and seven for the depression scale (HADS depression) [17] (Additional file 1). The scoring method consists of 0-never, 1-rarely, 2sometimes, 3-often and 4-almost always. Items from each of the 7-item anxiety and depression subscales were summed to generate a total subscale score. Total subscale scores of 7 or less indicate non-cases, 8-10 indicate borderline and scores of $\geq 11$ indicate definite cases [18]. It has been reported that the Chinese version of the HADS possesses excellent reliability and validity [19]. Parents were asked to read each statement and choose the answer that best described how they had felt in the preceding week [20]. The HADS was performed one day before the surgery.

\section{IXTQ}

The IXTQ has three components: a self-report of the child's own HRQOL completed by the child (5-17 years old), the Proxy IXTQ and a report of the child's HRQOL as completed by the parent [21]. An additional scale for the children's psychological and visual function and surgical opinions was completed by the parents. Each item had five response options: 100-Never, 75- Almost never, 50-Sometimes, 25-Often and 0-Almost always. For children aged 5-7 years, only three opinions were included: 100-not at all, 50-sometimes and 0-a lot. The IXTQ score for each child and their parents was calculated and ranged from 0 (worst) to 100 (best) HRQOL. During the HRQOL assessment, the children and their parents answered questionnaires separately without any verbal or nonverbal communication. Questionnaires were self-administered with written instructions and were supervised by the same investigator (QL). If the child or his/her parents had problems understanding the question, a verbal interview was conducted without any explanation or elaboration $[6,7,22]$. The IXTQ is available online in an administrable format with user instructions: https://public.jaeb.org/pedig/view/Reference. It was performed one day before the surgery and again at the final follow-up visit.

All the questionnaires used in this study were translated by the author using standardized procedures. The Chinese intermittent exotropia questionnaire was translated by two bilingual experts who were fluent in both Chinese and English. With only minor modifications, the Chinese questionnaire was consistent with the original questionnaire. Two English teachers from the United Kingdom then compared the reverse translation questionnaire with the original English version and found no significant differences.

\section{Statistical analysis}

Independent samples t-tests were used to compare the pre- and postoperative differences in HRQOL results between children of different ages and genders and their parents. Children with differences in stereo function and stereoscopic function were compared using one-way analysis of variance. Relationships among children, proxy HRQOL scores, HADS scores and severity of IXT were evaluated using multivariate linear regression analyses and Kendall's tau-b analysis. The SPSS 19.0 software package (SPSS Inc., Chicago, IL, USA) was used to perform these statistical analyses. A $P$-value of $\leq 0.05$ was required for results to be considered statistically significant.

\section{Results \\ Demographic data}

Of the 389 children included in this study, $47.8 \%$ were male and $52.2 \%$ were female. Their ages ranged from 5 to 17 years old (Mean $+\mathrm{SD}=8.17 \pm 2.81)$. The best corrected visual acuity was $-0.05 \pm 0.21(-0.1-0.2)$ in the right eye and $-0.05 \pm 0.1(0-0.2)$ in the left eye. The spherical equivalent of the right eye ranged from $-8.5 \mathrm{D}$ to $+9.25 \mathrm{D}(-0.08 \pm 2.38 \mathrm{D})$ and from $-10.5 \mathrm{D}$ to +8.25 $\mathrm{D}(-0.03 \pm 2.32 \mathrm{D})$ in the left eye (Table 1$)$. 
Table 1 Clinical characteristics of childhood intermittent exotropia

\begin{tabular}{|c|c|c|c|}
\hline Clinical characteristics & & & $N=(389)$ \\
\hline Sex (Male/Female) & & & $186 / 203$ \\
\hline Age (years, mean $\pm S D$ ) & & & $8.17 \pm 2.81(5-17)$ \\
\hline \multirow[t]{2}{*}{ VA of eyes (mean $\pm S D$ ) } & Left & & $-0.05 \pm 0.21(0.1-0.2)$ \\
\hline & Right & & $-0.05 \pm 0.1(0-0.2)$ \\
\hline \multirow[t]{2}{*}{ Deviation $(P D$, mean $\pm S D)$} & Near & & $31.08 \pm 9.92(10-64)$ \\
\hline & Distance & & $31.43 \pm 8.94(12-64)$ \\
\hline \multirow[t]{2}{*}{ Sensory fusion } & Normal (III) & & $82(21 \%)$ \\
\hline & Abnormal (Nil-II) & & $307(79 \%)$ \\
\hline \multirow[t]{6}{*}{ Stereoacuity (seconds) } & Near & Good ( $\leq 63 ")$ & $116(29.8 \%)$ \\
\hline & & Moderate $\left(\leq 200^{\prime \prime}\right)$ & $79(20.3 \%)$ \\
\hline & & Poor(> 200") & 194(49.9\%) \\
\hline & Distance & Good $\left(\leq 63^{\prime \prime}\right)$ & $25(6.4 \%)$ \\
\hline & & Moderate $\left(\leq 200^{\prime \prime}\right)$ & $41(10.5 \%)$ \\
\hline & & Poor(> 200") & $323(83.1 \%)$ \\
\hline Near control score (median,range) & & & $9(7-9)$ \\
\hline
\end{tabular}

$P D$ prism diopter; $V A$ visual acuity

\section{Severity of IXT and IXTQ scores}

The mean + SD IXTQ score in children with IXT was $48.21 \pm 26.2$, and their proxy score was $44.6 \pm 25.68$. The average score for psychological function, visual function and surgical opinions was $42.04 \pm 20.16$. The children's IXTQ scores were related to the proxy and comprehensive scales $(P<0.01)$ as well as to near stereoacuity $(\beta=$ $-6.41, P=0.029)$. There were no significant differences in HRQOL between children of different ages, angles of deviation or fusion functions (Figs. 1, 2 and 3). In the parent's scale, poor near stereoacuity was associated with lower scores $(\beta=-6.889, P=0.015)$. The angle of deviation at near showed negative linear relationships with visual function $(\beta=-1.05, P=0.026)$ and psychological

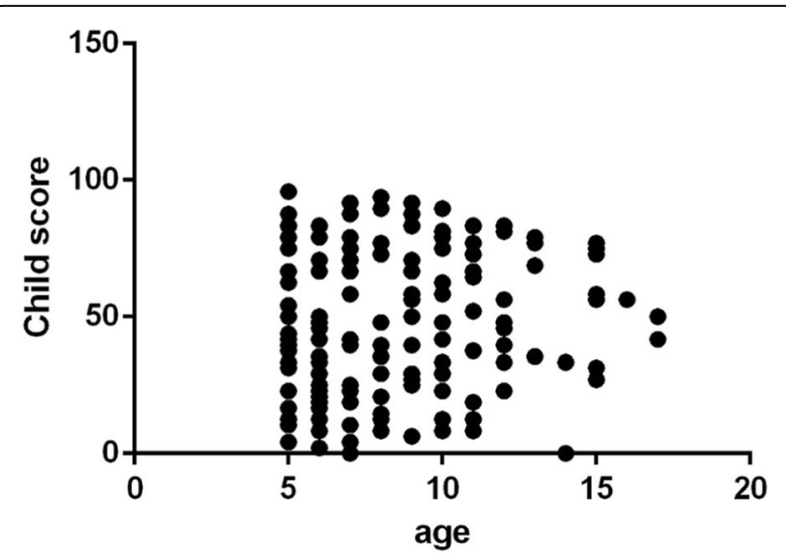

Fig. 1 Age was not correlative with the preoperative child $\mathrm{HRQOL}(P=0.68)$ scores $(\beta=-1.124, P=0.019)$ as well as opinion regarding surgery $(\beta=-1.146, P=0.024)$ (Table 2$)$.

\section{Severity of IXT and anxiety and depression scores}

The mean + SD anxiety and depression score of the parents was $11.2 \pm 2.92$, of which an anxiety scale score of $\geq 8$ accounted for $95.87 \%$, whereas a depression scale score of $\geq 8$ accounted for $92.01 \%$. The anxiety $(R=-$ $0.215, P=0.002)$ and depression $(\mathrm{R}=-0.182 P=0.009)$ scores showed a negative linear relationship with near stereoacuity. There were no statistically significant differences in other results of the IXT examination among the groups (Table 3).

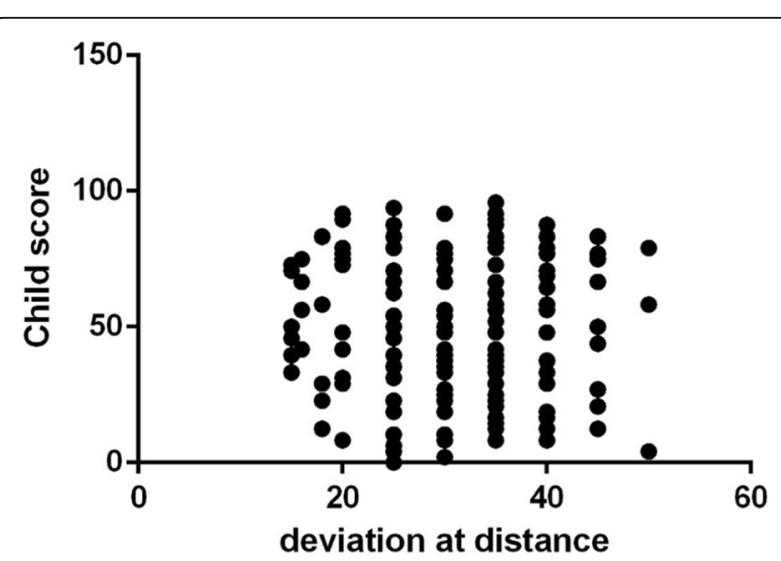

Fig. 2 The angle of deviation at distance was not correlative with the preoperative child $\mathrm{HRQOL}(\mathrm{P}=0.37)$ 


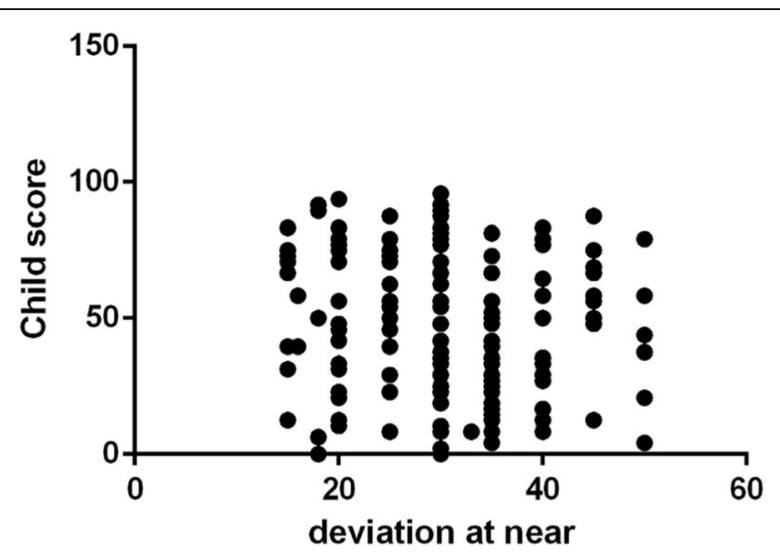

Fig. 3 The angle of deviation at near was not correlative with the preoperative child $\operatorname{HRQOL}(P=0.497)$

\section{Surgical outcomes and postoperative HRQOL}

Postoperative orthoptic measurements showed that 275 patients (70.6\%) achieved successful surgical results. Fifty-one patients (13.3\%) were overcorrected, and 63 patients (16.1\%) were undercorrected (Table 4).

All HRQOL scores in IXT children were higher after surgery than their preoperative scores $(P<0.05)$. The mean + SD IXTQ score in these children was $74.83 \pm$ 16.59 , and the proxy IXTQ score was $68.57 \pm 17.06$. The overall mean $+\mathrm{SD}$ score of the children's psychological, visual function and surgical opinions was $50.28 \pm 20.29$ (Table 5). Even in patients with over- and undercorrections (exotropia >10 PD, esotropia $>5 \mathrm{PD}$ ), postoperative IXTQ scores were significantly improved $(p=0.015)$. After surgery, the children's IXTQ score showed a negative linear relationship with the angle of deviation at distance $(\beta=-0.599, P=0.039)$, whereas no significant correlations in parental IXTQ scores were obtained with any of the clinical features. Visual function $(\beta=-0.856$, $P=0.036)$ and psychological scores $(\beta=-1.0, P=0.012)$ displayed a negative linear relationship with the angle of deviation at near vision (Table 6).

\section{Discussion}

Attempts at establishing a relationship between the child's HRQOL and clinical severity of their IXT have proven inconsistent based on previous literature. A multiethnic paediatric eye disease study (MEPEDS) [23] surveyed children with strabismus at 25 to 72 months of age and found that strabismus reduced the HRQOL in these preschool children. However, in that study, a wide variety of strabismus types were included in the analysis. In Wang et al.'s study, the deviation angle at distance and exotropia control at home were associated with the child's HRQOL [22], whereas Lim et al. believed that the child's HRQOL and clinical severity were not related [10]. Our current results were mixed; that is, the child's IXTQ was related to near stereoacuity but not to the deviation angle, NSC or distant stereoacuity. The clinical findings partially correspond with the child's HRQOL responses. Children's perception of strabismus differs from that of adults [24], in part due to the limited attention that children direct to their visual problems [25]. In particular, younger children have not yet formed a clear aesthetic concept and an established awareness of their eye disease. Essentially, strabismus is their norm and has little effect on their daily life [26]. Moreover, exotropia in children with IXT appears intermittently, which may also make it difficult for them to consistently respond to this condition and would thus not always affect their quality of life. In contrast, stereoscopic function is more

Table 2 Multivariate linear regression of the IXTQ and severity of IXT

\begin{tabular}{|c|c|c|c|c|c|c|}
\hline Examination of IXT & & Child score & Proxy score & Visual Function subscale & Psychological subscale & Surgery subscale \\
\hline & & $48.21 \pm 26.2$ & $44.6 \pm 25.68$ & $43.15 \pm 21.98$ & $41.7 \pm 22.32$ & $42.22 \pm 23.71$ \\
\hline \multirow[t]{4}{*}{ Deviation } & Near & $P=0.497$ & $P=0.422$ & $P=0.026^{*}$ & $P=0.019^{*}$ & $P=0.024^{*}$ \\
\hline & & $\beta=-3.86$ & $\beta=-0.362$ & $\beta=-1.05$ & $\beta=-1.124$ & $\beta=-1.146$ \\
\hline & Distance & $P=0.370$ & $P=0.114$ & $P=0.967$ & $P=0.773$ & $P=0.657$ \\
\hline & & $\beta=0.53$ & $\beta=0.908$ & $\beta=0.016$ & $\beta=0.112$ & $\beta=0.183$ \\
\hline \multirow[t]{2}{*}{ Sensory fusion } & & $P=0.837$ & $P=0.529$ & $P=0.388$ & $P=0.133$ & $P=0.960$ \\
\hline & & $\beta=1.558$ & $\beta=1.050$ & $\beta=-1.223$ & $\beta=2.165$ & $\beta=0.076$ \\
\hline \multirow[t]{4}{*}{ Stereoacuity } & Near & $P=0.029^{*}$ & $P=0.015^{*}$ & $P=0.521$ & $P=0.235$ & $P=0.274$ \\
\hline & & $\beta=-6.41$ & $\beta=-6.889$ & $\beta=-1.530$ & $\beta=-2.879$ & $\beta=2.811$ \\
\hline & Distance & $P=0.221$ & $P=0.412$ & $P=0.983$ & $P=0.635$ & $P=0.655$ \\
\hline & & $\beta=3.033$ & $\beta=0.293$ & $\beta=-0.042$ & $\beta=0.980$ & $\beta=-9.979$ \\
\hline \multirow[t]{2}{*}{ Near control score } & & $P=0.965$ & $P=0.061$ & $P=0.448$ & $P=0.372$ & $P=0.940$ \\
\hline & & $\beta=0.021$ & $\beta=-0.598$ & $\beta=-0.205$ & $\beta=-0.245$ & $\beta=-0.022$ \\
\hline
\end{tabular}

Both the child's and proxy scores were related to near stereoacuity. Subscales of visual function, psychological and surgical options were related to the angle of deviation at near. IXTQ: Intermittent Exotropia Questionnaire 
Table 3 Relationship between the severity of IXT and HADS

\begin{tabular}{|c|c|c|c|}
\hline Kendall's tau-b analysis & & Anxiety scale score & Depression scale score \\
\hline & & $11.2 \pm 2.92$ & $10.44 \pm 2.9$ \\
\hline \multirow[t]{2}{*}{ Deviation } & Near & $P=0.483$ & $P=0.072$ \\
\hline & Distance & $P=0.163$ & $P=0.946$ \\
\hline Sensory fusion & & $P=0.780$ & $P=0.756$ \\
\hline \multirow[t]{2}{*}{ Stereoacuity } & Near & $P=0.002$ & $P=0.019$ \\
\hline & Distance & $P=0.851$ & $P=0.359$ \\
\hline Near control score & & $P=0.293$ & $P=0.811$ \\
\hline
\end{tabular}

HADS scores were negatively correlated with near stereoacuity. HADS: Hospital Anxiety and Depression Scale

critical for detailed near works, and if disturbed, it may lead to children's inability to perform delicate operations $[27,28]$ and affect their social activities [29]. With poor stereopsis, it is much harder to judge where objects are in space and estimate the distance between one's hand and the object. An easy task, such as catching a ball or taking steps, may become difficult for these children [30, 31 . With no stereopsis, people walk $10 \%$ slower than normal [32]. Patients with IXT experience an initial decline in distance stereoacuity followed by a decline in near stereoacuity. Before the impairment of near stereoacuity, those problems have not yet shown up, and as IXT worsens, the problems become increasingly serious. Our findings that children in the later stages of IXT show effects on their HRQOL may be related to the disturbance of stereoscopic function.

Parents' proxy scale scores were also related to near stereoacuity, and the subscale scores of psychological, visual function and surgery opinion had a negative relationship with the deviation angle at near. These results indicate that not only do the later stages of IXT affect the parents' HRQOL but also that deviations at near represent their greatest concern. As near deviation can be readily detected by parents, it seems understandable that they would worry that this IXT affects their children's physical and mental health. These parents would observe the frequency and severity of their children's near deviation and, therefore, be more inclined to take their children to see a doctor as well as be more concerned about the surgical risk and surgical prognosis. Wang et al. [22] found that both the child's and their parents' HRQOL showed a trend towards $>$ correlating with clinical severity, with large deviation, poor control and poor stereo function being significantly associated with higher IXTQ scores. In our experience, we found that some patients with a more serious IXT may show a lower HRQOL score, which then predisposes them to ignore the severity of IXT and thereby delays the time for surgery. In fact, the relationship between the angle of deviation, stereoacuity and fusion function is not yet clearly defined [33], but the larger the angle of deviation is, the more likely it will be to disrupt the binocular balance [34]. A loss of stereoacuity in children may result in abnormal daily activity that is readily apparent.

Table 4 Clinical characteristics after surgery

\begin{tabular}{|c|c|c|c|}
\hline \multicolumn{3}{|l|}{ Clinical characteristics } & \multirow{2}{*}{$\begin{array}{l}\mathbf{N}=(\mathbf{3 8 9}) \\
11.49 \pm 6.17\end{array}$} \\
\hline Deviation at distance $(P D$, mean $\pm S D)$ & Overcorrected & & \\
\hline & Successful & & $-1.69 \pm 3.75$ \\
\hline & Undercorrected & & $-14.6 \pm 3.29$ \\
\hline \multirow[t]{2}{*}{ Sensory fusion } & Normal (III) & & $120(30.8 \% \%)$ \\
\hline & Abnormal (Nil-II) & & $296(69.2 \%)$ \\
\hline \multirow[t]{2}{*}{ Stereoacuity (seconds) } & Near & Good $\left(\leq 63^{\prime \prime}\right)$ & $121(31.1 \%)$ \\
\hline & & Moderate $\left(\leq 200^{\prime \prime}\right)$ & $108(27.7 \%)$ \\
\hline \multirow[t]{4}{*}{ Sensory fusion } & & Poor(> 200") & $160(41.1 \%)$ \\
\hline & Distance & Good ( $\leq 63 ")$ & $21(5.3 \%)$ \\
\hline & & Moderate $\left(\leq 200^{\prime \prime}\right)$ & $36(9.25)$ \\
\hline & & Poor(> 200") & $332(85.3 \%)$ \\
\hline
\end{tabular}

PD prism diopter; $V A$ visual acuity

Overcorrected:esotropia $>$ 5PD

Successful: exotropia of $\leq 10 P D$ and esotropia $\leq 5 P D$

Undercorrected: exotropia $>10 P D$ 
Table 5 Pre- and post-operative IXTQ scores in childhood intermittent exotropia

\begin{tabular}{llll}
\hline IXTQ & Preoperative & Postoperative & $\boldsymbol{P}$ values \\
\hline Child score & $48.21 \pm 26.2$ & $74.83 \pm 16.59$ & $\mathbf{0 . 0 0 1}$ \\
Proxy score & $44.6 \pm 25.68$ & $68.57 \pm 17.06$ & $\mathbf{0 . 0 0 1}$ \\
Average score & $42.04 \pm 20.16$ & $50.28 \pm 20.29$ & $\mathbf{0 . 0 0 1}$
\end{tabular}

Differences between pre- and post-operative IXTQ scores were statistically significant

Overall, the objective clinical findings of IXT do not provide a good representation for the subjective understanding of the disease in these children. Preoperative HRQOL is related to the later stages of impaired stereoacuity in children with IXT and may provide a slight guide for clinicians to judge the severity of IXT and the time for surgical intervention. However, these HRQOL scores are not in full accord with the severity of IXT. Therefore, it is important for clinicians to inform parents about all aspects of IXT, including the various clinical features and surgical versus nonsurgical interventions, that may help them to make the appropriate decision.

The results of the anxiety and depression scores from parents indicate that they exhibit an obvious tendency for anxiety and depression regarding their children's IXT. It is clear that the parents are truly concerned about their children with IXT, as more than $90 \%$ of them show a decline in mental health. We found that the decline in near stereoacuity can result in a significant amount of anxiety and depression, although there is no correlation with other factors, such as deviation angle, NSC and distance stereoacuity. It has been reported that visual impairment and loss of binocular function are related to symptoms of anxiety and depression [35].
Decreasing near stereoacuity results in deterioration in reading abilities and academic performance [36, 37], and reduced stereoacuity function also limits career options for the future [31]. Some of them may avoid performing activities that may bring attention to their defects [38]. With the decline in binocular function in the later stages of IXT, these children can face poor academic performance and a negative attitude towards strabismus by their peers. These problems may cause anxiety or depression in their parents. The results from a prospective study by Chai et al. [39] revealed that children, adolescents or adults with strabismus may experience symptoms of anxiety and depression and that children are more affected and less likely to recover their emotional and mental state. Mcbain [16] and Snaith [40] emphasized that it was society's and patient's awareness of the disease that affected the quality of life, not the severity of the disease itself. Our results also confirm this finding. Almost all parents show signs of psychological stress in response to the various degrees of IXT severity in their children, which can explain their anxiety and likelihood of taking their children to the hospital for treatment.

The postoperative HRQOL in both children and their parents significantly improved, likely due to the changes in the child's appearance after surgery [41]. In fact, all subscales of IXTQ scores show improvements after surgery. It is generally believed that both the cosmetic and the functional recovery of binocular vision following surgery result in a positive impact on the social skills, emotions and mental state of these children. These postoperative HRQOL scores showed a significant relationship with the eye position, and even in patients with under- or overcorrections resulting from strabismus surgery, their postoperative HRQOL scores were

Table 6 Multivariate linear regression of surgical outcomes and post-operative IXTQ

\begin{tabular}{|c|c|c|c|c|c|c|}
\hline Examination of IXT & & Child score & Proxy score & Function subscale & Psychological subscale & Surgery subscale \\
\hline & & $74.83 \pm 16.59$ & $68.57 \pm 17.06$ & $60.03 \pm 44.60$ & $53.65 \pm 24.32$ & $37.16 \pm 21.43$ \\
\hline \multirow[t]{4}{*}{ Deviation } & Near & $P=0.912$ & $P=0.215$ & $P=0.036^{*}$ & $P=0.012^{*}$ & $P=0.360$ \\
\hline & & $\beta=0.036$ & $\beta=-0.415$ & $\beta=-0.865$ & $\beta=-1.000$ & $\beta=-0.353$ \\
\hline & Distance & $P=0.039^{*}$ & $P=0.707$ & $P=0.406$ & $P=0.135$ & $P=0.051$ \\
\hline & & $\beta=-0.599$ & $\beta=-0.129$ & $\beta=-0.302$ & $\beta=0.608$ & $\beta=-0.770$ \\
\hline \multirow[t]{2}{*}{ Sensory fusion } & & $P=0.473$ & $P=0.789$ & $P=0.701$ & $P=0.529$ & $P=0.057$ \\
\hline & & $\beta=-0.580$ & $\beta=-0.221$ & $\beta=0.391$ & $\beta=-0.618$ & $\beta=2.104$ \\
\hline \multirow[t]{4}{*}{ Stereoacuity } & Near & $P=0.542$ & $P=0.606$ & $P=0.265$ & $P=0.746$ & $P=0.853$ \\
\hline & & $\beta=-0.800$ & $\beta=-0.691$ & $\beta=1.841$ & $\beta=0.516$ & $\beta=0.331$ \\
\hline & Distance & $P=0.878$ & $P=0.594$ & $P=0.508$ & $P=0.065$ & $P=0.731$ \\
\hline & & $\beta=-0.278$ & $\beta=0.986$ & $\beta=-1.509$ & $\beta=-4.062$ & $\beta=0.205$ \\
\hline \multirow[t]{2}{*}{ Near control score } & & $P=0.835$ & $P=0.119$ & $P=0.144$ & $P=0.632$ & $P=0.621$ \\
\hline & & $\beta=-0.091$ & $\beta=0.700$ & $\beta=0.807$ & $\beta=-0.165$ & $\beta=-0.173$ \\
\hline
\end{tabular}

Children' IXTQ scores were related to the angle of deviation at distance. Psychological and visual function scores were negatively related to the angle of deviation at near. No statistically significant correlations were obtained between parental IXTQ scores and any of the clinical features 
substantially improved. Interestingly, these changes in psychological state may not parallel the surgical outcome. For example, Mruthyunjaya et al. [42] noted that subjective satisfaction can be obtained when the eye position is within 10 PD after surgery, even if it is objectively considered unsuccessful by the surgeon. Archer et al. [43] also reported that although strabismus surgery in children can improve their HRQOL, there was no statistically significant difference between successful and unsuccessful surgical outcomes in patients. Another explanation was that as a parent, they would evaluate the quality of life of their own child as significantly more highly after low-risk strabismus surgery, regardless of any functional outcome. This is similar to the findings of our study. Strabismus surgery can produce a similar degree of comfort and reduce the patient's concern about their disease as that in response to a placebo. After surgery, children's HRQOL scores were consistent with those of their parents. Perhaps the surgery enables both the children and their parents to attend similarly to the IXT.

There are certain limitations in this study. Currently, no unified criteria exist for the judgement of IXT severity. Different methods used for measuring stereoacuity and fusion function may reveal quite different results. In addition, there were a few children in this study with a history of amblyopia treatment, and some wore glasses, which may affect their HRQOL. Finally, we did not have a healthy control group, and the fact that all patients in our study underwent strabismus surgery may introduce some bias with regard to the whole population of children with IXT.

\section{Conclusion}

Children's and parents' HRQOOL scores and anxiety and depression scores were associated with near stereoacuity. The improvements in HRQOL scores in both the children and the parents following surgery indicate that timely surgery is important for enhancing the quality of life of these children. However, HRQOL scores failed to reflect the seriousness of childhood IXT, nor could these scores be used as an indication for surgical intervention. It is important to note that HRQOL scores vary widely between people as well as with the same illness within an individual over time, as these scores are based on personal assessments and are influenced by physical, psychological and social factors [44]. Nonetheless, these HRQOL scores should be considered by the clinician when evaluating children with IXT to understand the anxiety of these children and their parents and attend to their psychological state.

\section{Abbreviations}

HRQOL: Health-related quality of life; HADS: Hospital anxiety and depression scale; IXT: Intermittent exotropia; IXTQ: Intermittent Exotropia Questionnaire

\section{Supplementary Information}

The online version contains supplementary material available at https://doi. org/10.1186/s12886-021-02027-w.

Additional file 1. Hospital Anxiety and Depression Scale (HADS). The 14 items comprising the HADS serve to measure anxiety and depression symptoms, with seven items for the anxiety scale (HADS anxiety) and seven for the depression scale (HADS depression).

\section{Acknowledgements}

We sincerely appreciate Jing Lin for assistance with the research and Jianhua Yan for valuable discussion. Our manuscript has been added to a preprint server called Research Square, and the DOI is https://doi.org/10.21203/rs.3.rs23146/v1.

\section{Authors' contributions}

Conceptualization, J.H.Y.; Methodology, J.H.Y., D.Y.M., J.L., L.N.C. and J.Y.L.; Validation, J.H.Y.; Formal analysis, D.Y.M.; Resources, J.H.Y., L.J., L.N.C. and J.Y.L.; Data curation, J.H.Y., D.Y.M., L.J., L.N.C. and J.Y.L.; Writing-original draft preparation, D.Y.M and L.J.; Writing-review and editing, J.H.Y.; Visualization, D.Y.M. and L.J.; Supervision, J.H.Y.; Project administration, J.H.Y.; Funding acquisition, J.H.Y. The author(s) read and approved the final manuscript.

\section{Funding}

This work was supported by the National Natural Science Foundation of China (Grant number:81670885). The funders had no role in the study design, data collection and analysis, decision to publish or preparation of the manuscript. No additional external funding was received for this study.

\section{Availability of data and materials}

The datasets used and/or analysed during the current study are available from the corresponding author on reasonable request.

\section{Declarations}

Ethical approval and consent to participate

All participants in this study provided consent to participate. The parents or guardians provided consent for participants under the age of 18 . We explained the nature of the study to all patients and verbal informed consent was obtained prior to participation. The human ethics committee of the Zhongshan Ophthalmic Center of Sun Yat-sen University waived further processing, since the use of questionnaires within normal clinical practice does not, require formal approval, and only verbal consent is needed. Ethical approval was obtained from the human ethics committee of the Zhongshan Ophthalmic Center of Sun Yat-sen University, China (approval NO. 2020KYPJ068)

Consent for publication

Not Applicable.

Competing interests

The authors declare that they have no competing interests.

Received: 24 September 2020 Accepted: 17 June 2021

Published online: 30 June 2021

\section{References}

1. Mohney BG, Huffaker RK. Common forms of childhood exotropia. Ophthalmology. 2003;110(11):2093-6. https://doi.org/10.1016/j.ophtha.2003. 04.001 .

2. Govindan M, Mohney BG, Diehl NN, Burke JP. Incidence and types of childhood exotropia: a population-based study. Ophthalmology. 2005; 112(1):104-8. https://doi.org/10.1016/j.ophtha.2004.07.033.

3. Pan C-W, Zhu H, Yu J-J, Ding H, Bai J, Chen J, et al. Epidemiology of intermittent exotropia in preschool children in China. Optom Vis Sci. 2016; 93(1):57-62. https://doi.org/10.1097/OPX.0000000000000754.

4. Fu J, Li SM, Liu LR, Li JL, Li SY, Zhu BD, et al. Prevalence of amblyopia and strabismus in a population of 7th-grade junior high school students in Central China: the Anyang childhood eye study (ACES). Ophthalmic 
Epidemiol. 2014;21 (3):197-203. https://doi.org/10.3109/09286586.2014.9043 71.

5. Romanchuk KG, Dotchin SA, Zurevinsky J. The natural history of surgically untreated intermittent exotropia-looking into the distant future. J Am Assoc Pediatr Ophthalmol Strabismus. 2006;10(3):225-31. https://doi.org/1 0.1016/j.jaapos.2006.02.006

6. Yamada T, Hatt SR, Leske DA, Holmes JM. Health-related quality of life in parents of children with intermittent exotropia. J Am Assoc Pediatr Ophthalmol Strabismus. 2011;15(2):135-9. https://doi.org/10.1016/j.jaapos.2 010.11.020.

7. Hatt SR, Leske DA, Yamada T, Bradley EA, Cole SR, Holmes JM. Development and initial validation of quality-of-life questionnaires for intermittent exotropia. Ophthalmology. 2010;117:163-168. e1.

8. Zigmond A, Snaith R. The hospital anxiety and depression scale. Acta Psychiatr Scand. 1983;67(6):361-70. https://doi.org/10.1111/j.1600-0447.1983. tb09716.x.

9. Hatt SR, Leske DA, Liebermann L, Holmes JM. Symptoms in children with intermittent exotropia and their impact on health-related quality of life. Strabismus. 2016;24(4):139-45. https://doi.org/10.1080/09273972.2016.1242 640.

10. Lim SB, Wong WL, Ho R, Wong I. Childhood intermittent exotropia from a different angle: does severity affect quality of life? $\mathrm{Br} J$ Ophthalmol. 2015; 99(10):1405-11. https://doi.org/10.1136/bjophthalmol-2014-306545.

11. Hatt SR, Leske DA, Liebermann L, Mohney BG, Brodsky MC, Yamada T, et al. Associations between health-related quality of life and the decision to perform surgery for childhood intermittent exotropia. Ophthalmology. 2014; 121(4):883-8. https://doi.org/10.1016/.ophtha.2013.10.029.

12. Chiu AK, Din N, Ali N. Standardising reported outcomes of surgery for intermittent exotropia-a systematic literature review. Strabismus. 2014;22(1): 32-6. https://doi.org/10.3109/09273972.2013.877940.

13. McKenzie JA, Capo JA, Nusz KJ, Diehl NN, Mohney BG. Prevalence and sex differences of psychiatric disorders in young adults who had intermittent exotropia as children. Arch Ophthalmol. 2009;127(6):743-7. https://doi.org/1 0.1001/archophthalmol.2009.68

14. Bez Y, Coşkun E, Erol K, Cingu AK, Eren Z, Topçuoğlu V, et al. Adult strabismus and social phobia: a case-controlled study. J Am Assoc Pediatr Ophthalmol Strabismus. 2009;13(3):249-52. https://doi.org/10.1016/j.jaapos.2 009.02.010.

15. Jackson S, Harrad R, Morris M, Rumsey N. The psychosocial benefits of corrective surgery for adults with strabismus. Br J Ophthalmol. 2006;90(7): 883-8. https://doi.org/10.1136/bjo.2005.089516.

16. McBain HB, MacKenzie KA, Au C, Hancox J, Ezra DG, Adams GG, et al. Factors associated with quality of life and mood in adults with strabismus. $\mathrm{Br} J$ Ophthalmol. 2014;98(4):550-5. https://doi.org/10.1136/bjophthalmol-2013-304220

17. Djukanovic I, Carlsson J, Årestedt K. Is the hospital anxiety and depression scale (HADS) a valid measure in a general population 65-80 years old? A psychometric evaluation study. Health Qual Life Outcomes. 2017;15(1):193. https://doi.org/10.1186/s12955-017-0759-9.

18. Roberts SB, Bonnici DM, Mackinnon AJ, Worcester MC. Psychometric evaluation of the hospital anxiety and depression scale (HADS) among female cardiac patients. Br J Health Psychol. 2001;6(4):373-83. https://doi. org/10.1348/135910701169278.

19. Leung $\mathrm{CM}$, Ho S, Kan CS, Hung $\mathrm{CH}$, Chen CN. Evaluation of the Chinese version of the Hospital Anxiety and Depression Scale. A cross-cultural perspective. Int J Psychosom. 1993:40(1-4):29-34.

20. Chan Y-F, Leung DY, Fong DY, Leung C-M, Lee AM. Psychometric evaluation of the hospital anxiety and depression scale in a large community sample of adolescents in Hong Kong. Qual Life Res. 2010;19(6):865-73. https://doi. org/10.1007/s11136-010-9645-1.

21. Hatt SR, Leske DA, Adams WE, Kirgis PA, Bradley EA, Holmes JM. Quality of life in intermittent exotropia: child and parent concerns. Arch Ophthalmol. 2008;126(11):1525-9. https://doi.org/10.1001/archopht.126.11.1525.

22. Wang, Y., M. Xu, H. Yu, J. Xu, F. Hou, J. Zhou, and X. Yu, Health-related quality of life correlated with the clinical severity of intermittent exotropia in children. Eye. 2020;34:400-07.

23. Wen G, McKean-Cowdin R, Varma R, Tarczy-Hornoch K, Cotter SA, Borchert $\mathrm{M}$, et al. General health-related quality of life in preschool children with strabismus or amblyopia. Ophthalmology. 2011;118(3):574-80. https://doi. org/10.1016/j.ophtha.2010.06.039.

24. Schuster AK, Elflein HM, Pokora R, Schlaud M, Baumgarten F, Urschitz MS. Health-related quality of life and mental health in children and adolescents with strabismus-results of the representative population-based survey KiGGS. Health Qual Life Outcomes. 2019;17(1):81. https://doi.org/10.1186/s12 955-019-1144-7.

25. Hatt SR, Leske DA, Holmes JM. Awareness of exodeviation in children with intermittent exotropia. Strabismus. 2009;17(3):101-6. https://doi.org/10.1080/ 09273970903107972.

26. Yamada T, Hatt SR, Leske DA, Holmes JM. Specific health-related quality of life concerns in children with intermittent exotropia. Strabismus. 2012;20(4): 145-51. https://doi.org/10.3109/09273972.2012.735338.

27. Grant S, Suttle C, Melmoth DR, Conway ML, Sloper JJ. Age-and stereovisiondependent eye-hand coordination deficits in children with amblyopia and abnormal binocularity. Investig Ophthalmol Vis Sci. 2014;55(9):5687-701. https://doi.org/10.1167/iovs.14-14745.

28. Suttle CM, Melmoth DR, Finlay AL, Sloper JJ, Grant S. Eye-hand coordination skills in children with and without amblyopia. Investig Ophthalmol Vis Sci. 2011;52(3):1851-64. https://doi.org/10.1167/iovs.10-6341.

29. Smith D, Ropar D, Allen HA. Does stereopsis account for the link between motor and social skills in adults? Molecular Autism. 2018;9(1):55. https://doi. org/10.1186/s13229-018-0234-4.

30. Mazyn LI, Lenoir M, Montagne G, Savelsbergh GJ. The contribution of stereo vision to one-handed catching. Exp Brain Res. 2004;157(3):383-90. https:// doi.org/10.1007/s00221-004-1926-X.

31. Levi DM, Knill DC, Bavelier D. Stereopsis and amblyopia: a mini-review. Vis Res. 2015;114:17-30. https://doi.org/10.1016/j.visres.2015.01.002.

32. Hayhoe M, Gillam B, Chajka K, Vecellio E. The role of binocular vision in walking. Vis Neurosci. 2009;26(1):73-80. https://doi.org/10.1017/S0952523 808080838.

33. Superstein R, Dean TW, Holmes JM, Chandler DL, Cotter SA, Wallace DK, et al. Relationship among clinical factors in childhood intermittent exotropia. J Am Assoc Pediatr Ophthalmol Strabismus. 2017;21(4):268-73. https://doi.org/10.1016/j.jaapos.2017.04.005.

34. Ahn SJ, Yang HK, Hwang J-M. Binocular visual acuity in intermittent exotropia: role of accommodative convergence. Am J Ophthalmol. 2012; 154:981-986. e3.

35. Eramudugolla R, Wood J, Anstey KJ. Co-morbidity of depression and anxiety in common age-related eye diseases: a population-based study of 662 adults. Front Aging Neurosci. 2013;5:56.

36. Kulp M, Schmidt P. A pilot study. Depth perception and near stereoacuity: is it related to academic performance in young children? Binocular Vision Strabismus Quarterly. 2002;17:129-34 discussion 133.

37. Kulp MT, Schmidt PP. Visual predictors of reading performance in kindergarten and first grade children. Optometry Vision Sci. 1996;73(4):25562. https://doi.org/10.1097/00006324-199604000-00007.

38. Menon V, Saha J, Tandon R, Mehta M, Khokhar S. Study of the psychosocial aspects of strabismus. J Pediatr Ophthalmol Strabismus. 2002;39(4):203-8. https://doi.org/10.3928/0191-3913-20020701-07.

39. Chai Y, Shao Y, Lin S, Xiong K, Chen W, Li Y, et al. Vision-related quality of life and emotional impact in children with strabismus: a prospective study. J Int Med Res. 2009;37(4):1108-14. https://doi.org/10.1177/147323000903 700415.

40. Snaith RP. The hospital anxiety and depression scale. Health Qual Life Outcomes. 2003;1(1):29. https://doi.org/10.1186/1477-7525-1-29.

41. Nelson BA, Gunton KB, Lasker JN, Nelson LB, Drohan LA. The psychosocial aspects of strabismus in teenagers and adults and the impact of surgical correction. J Am Assoc Pediatr Ophthalmol Strabismus. 2008;12:72-76. e1.

42. Mruthyunjaya P, Simon JW, Pickering JD, Lininger LL. Subjective and objective outcomes of strabismus surgery in children. J Pediatr Ophthalmol Strabismus. 1996;33(3):167-70. https://doi.org/10.3928/0191-3913-1996050109.

43. Archer SM, Musch DC, Wren PA, Guire KE, Del Monte MA. Social and emotional impact of strabismus surgery on quality of life in children. J Am Assoc Pediatr Ophthalmol Strabismus. 2005;9(2):148-51. https://doi.org/10.1 016/j.jaapos.2004.12.006.

44. Wang Z, Zhou J, Xu Y, Yin H, She X, Bian W, et al. Development of a conceptual model regarding quality of life in Chinese adult patients with strabismus: a mixed method. Health Qual Life Outcomes. 2018;16(1):171. https://doi.org/10.1186/s12955-018-0991-y.

\section{Publisher's Note}

Springer Nature remains neutral with regard to jurisdictional claims in published maps and institutional affiliations. 